\title{
Controle biológico da mancha-aquosa do melão por compostos bioativos produzidos por Bacillus spp.
}

\author{
Elizama Roza Santos ${ }^{1}$, Ester Ribeiro Gouveia ${ }^{1}$, Rosa Lima Ramos Mariano ${ }^{2,3}$, Ana Maria Souto-Maior ${ }^{1}$
}

\begin{abstract}
${ }^{1}$ Universidade Federal de Pernambuco, Departamento de Antibióticos, CEP 50670-901, Recife, PE, Brasil. E-mail: soutomaior@ufpe.br. ${ }^{2}$ Universidade Federal Rural de Pernambuco, Departamento de Agronomia, CEP 52171-900, Recife, PE, Brasil. E-mail: rmariano@truenet.com.br. Parte da Dissertação de Mestrado do primeiro autor, apresentada à Universidade Federal de Pernambuco. ${ }^{3}$ Bolsista de Produtividade em Pesquisa do CNPq.
\end{abstract}

Autor para correspondência: Rosa L. R. Mariano.

Data de chegada: 20/08/2004. Aceito para publicação em: 03/10/2005.

\section{ABSTRACT}

Santos, E.R.; Gouveia, E.R.; Mariano, R.L.R.; Souto-Maior, A.M. Biocontrol of bacterial fruit blotch of melon by bioactive compounds produced by Bacillus spp. Summa Phytopathologica, v.32, n.4, p.376-378, 2006.

The bacterial fruit blotch, caused by the bacterium Acidovorax avenae subsp. citrulli (Aac), is responsible for great losses in melon production. The control of this disease was investigated in vivo by treating infected yellow melon seeds with fermented broths of $B$. subtilis R14, $B$. megaterium pv. cerealis RAB7, B. pumilus $\mathrm{C} 116$ and Bacillus sp. MEN2, with and without bacterial cells. The mechanism of action of the strains was studied in vitro by the agar diffusion technique. The bioactive compounds produced were partially characterized by hemolysis test and surfactant activity. Regarding the tests conducted in vivo there was no statistical difference between the treatments with and without bacterial cells, which indicated that the control was due to the presence of bioactive compounds produced during fermentations. All treatments were different from the control $(\mathrm{P}=0.05 \%)$ but they did not differ among them. The B. megaterium pv. cerealis RAB7 reduced disease incidence $(89.1 \%)$, disease index $(92.7 \%)$, increased the incubation period from 9.8 to 11.9 days and reduced the area under disease progress curve from 3.36 to 0.17 . In the in vitro tests, all strains showed antibiosis against Aac and the bioactive compounds were partially characterized as lipopeptides.

Additional keywords: Cucumis melo, Acidovorax avenae subsp. citrulli, Bacillus subtilis, B. megaterium pv. cerealis, B. pumilus.

\section{RESUMO}

Santos, E.R.; Gouveia, E.R.; Mariano, R.L.R.; Souto-Maior, A.M. Controle biológico da mancha-aquosa do melão por compostos bioativos produzidos por Bacillus spp. Summa Phytopathologica, v.32, n.4, p.376-378, 2006.

A mancha-aquosa, causada por Acidovorax avenae subsp. citrulli (Aac) causa grandes prejuízos à cultura do melão. O controle dessa doença foi estudado in vivo, com microbiolização de sementes de melão Amarelo infectadas, com líquidos fermentados de Bacillus subtilis R14, B. megaterium pv. cerealis RAB7, B. pumilus C116 e Bacillus sp. MEN2, com e sem células bacterianas. O mecanismo de ação dos isolados foi estudado in vitro pelo método de difusão em ágar e os compostos bioativos parcialmente caracterizados por testes de hemólise e atividade surfactante. Nos testes in vivo, não houve diferença significativa entre os tratamentos com e sem células, indicando que o controle ocorreu devido à presença de compostos bioativos produzidos durante as fermentações. Todos os tratamentos diferiram da testemunha sem diferir entre si $(\mathrm{P}=0,05 \%)$. B. megaterium pv. cerealis RAB7 proporcionou redução da incidência $(89,1 \%)$ e do índice de doença $(92,7 \%)$, elevou o período de incubação da mancha-aquosa de 9,8 para 11,9 dias e reduziu a AACPD de 3,36 para 0,17 . In vitro, todos isolados apresentaram antibiose contra Aac e os compostos bioativos foram parcialmente caracterizados como lipopeptídeos.

Palavras-chave adicionais: Cucumis melo, Acidovorax avenae subsp. citrulli, Bacillus subtilis, B. megaterium pv. cerealis, B. pumilus

A mancha-aquosa do melão, causada pela bactéria Acidovorax avenae subsp. citrulli (Aac), é uma doença importante que tem causado grandes prejuízos no Nordeste do Brasil, principalmente no Ceará e Rio Grande do Norte, que são os maiores produtores dessa cucurbitácea (8).

Os objetivos deste trabalho foram testar líquidos produzidos pela fermentação de isolados de Bacillus com e sem células bacterianas, no controle da mancha-aquosa do melão pelo tratamento de sementes infectadas; estudar o mecanismo de ação in vitro desses isolados e caracterizar parcialmente os compostos bioativos produzidos.

Foram utilizados quatro isolados de Bacillus: B. subtilis R14, B. megaterium pv. cerealis RAB7, B. pumilus C116 e Bacillus sp. MEN2, os quais foram mantidos em meio ágar nutritivo e fermentados em meio proposto por Kim et al. (2) modificado, contendo em g/L: glicose, $40 ; \mathrm{K}_{2} \mathrm{HPO}_{4}, 10,5 ;\left(\mathrm{NH}_{4}\right)_{2} \mathrm{SO}_{4}, 11,5 ; \mathrm{MgSO}_{4} \cdot 7 \mathrm{H} 2 \mathrm{O}, 0,5$; $\mathrm{NaH}_{2} \mathrm{PO}_{4} \cdot 2 \mathrm{H}_{2} \mathrm{O}, 1,7 ; \mathrm{MnSO}_{4} \cdot \mathrm{H}_{2} \mathrm{O}, 0,04$ e extrato de levedura, 0,5 ; 
pH 8,0. O fitopatógeno, isolado Aac1, foi obtido da coleção do Laboratório de Fitobacteriologia da Universidade Federal Rural de Pernambuco, sendo mantido e cultivado para preparo de inóculo em meio ágar nutritivo-extrato de levedura-dextrose (NYDA) (4).

Bacillus spp. foram cultivados em meio caldo nutritivo durante 24 horas a $30^{\circ} \mathrm{C}$, quando suspensões de cada isolado foram preparadas (McFarland $1,5 \times 10^{9} \mathrm{cel} / \mathrm{mL}$ ), e $25 \mathrm{~mL}$ colocados em frascos Fernbach, contendo $500 \mathrm{~mL}$ do meio de fermentação. Os frascos foram acondicionados em mesa incubadora rotativa, a $30{ }^{\circ} \mathrm{C}$ e $150 \mathrm{rpm}$, durante 72 horas.

O patógeno Aac1 foi cultivado em NYDA por 36 horas, suspendido em água destilada esterilizada e inoculado em sementes de melão tipo Amarelo, pelo método de infiltração a vácuo (3). Após secagem sobre papel toalha, as sementes inoculadas foram conservadas em sacos de papel a $25 \pm 2{ }^{\circ} \mathrm{C}$ durante 7 dias, quando foram microbiolizadas por imersão durante 30 minutos, no líquido fermentado filtrado ou não, ou seja, contendo ou não as células de Bacillus spp. Ao inóculo foi adicionada uma gota do espalhante adesivo Tween 80 a $0,05 \%$ e a testemunha relativa foi tratada com água destilada contendo Tween. Após a microbiolização e secagem por 24 horas a $25 \pm 2{ }^{\circ} \mathrm{C}$, as sementes foram plantadas em bandejas de poliestireno Plantágil ${ }^{\circledR}$ contendo substrato comercial Plantmax ${ }^{\circledR}$. Para facilitar a expressão dos sintomas, após a emergência das plântulas foi feita uma câmara úmida com plástico transparente. A eficiência dos isolados de Bacillus no controle da doença foi avaliada pelas variáveis: período de incubação $(\mathrm{PI})=$ número de dias transcorridos do plantio até o aparecimento dos sintomas; incidência $(\mathrm{INC})=$ porcentagem ou proporção de plantas doentes; e severidade $=$ porcentagem da área coberta por sintomas da doença, estimada com auxílio de escala de notas (10). Com os dados diários de severidade foi calculada a área abaixo da curva de progresso da doença (AACPD) pela expressão: AACPD $=\left\{\left[\mathrm{i}\left(\mathrm{y}+\mathrm{y}_{\mathrm{i}+1}\right) / 2 . \mathrm{d}_{\mathrm{ti}}\right] / \mathrm{n}\right\}$; onde $\mathrm{y}_{\mathrm{i}}$ e $\mathrm{y}_{\mathrm{i}+1}$ são os valores de severidade observados em duas avaliações consecutivas, $\mathrm{d}_{\mathrm{ti}} \mathrm{o}$ intervalo entre as avaliações e na duração do período de avaliação (9). Com a severidade final, calculou-se o índice de doença (IDO) pela fórmula de McKinney (5).
$\mathrm{O}$ experimento teve delineamento inteiramente casualizado em arranjo fatorial 4 × 2, sendo quatro isolados de Bacillus e dois tipos de líquido fermentado, com e sem células. Cada tratamento teve quatro repetições com 16 plântulas. A testemunha relativa foi tratada apenas com água destilada. Os dados foram submetidos à análise de variância e as médias foram comparadas pelo teste de Tukey $(\mathrm{P}=0,05)$.

Para verificar a existência de antibiose, foram realizados testes de atividade antimicrobiana in vitro, utilizando blocos de gelose e discos contendo líquido fermentado filtrado, pelo método de difusão em meio NYDA. As placas foram incubadas a $30^{\circ} \mathrm{C}$ e as leituras dos diâmetros dos halos realizadas após 24 horas.

Para caracterizar parcialmente os compostos bioativos, foram realizados testes de atividade hemolítica e surfactante, que são indicadores da produção de lipopeptídeos. No teste de hemólise, os antagonistas foram aplicados em quatro pontos eqüidistantes com palitos estéreis sobre a superfície do meio ágar sangue (composição em g/L: extrato de carne, 10; peptona, $10 ; \mathrm{NaCl}, 5$; ágar, 15; e sangue de carneiro, 50; $\mathrm{pH} 7,0)$ em placas de Petri, as quais foram incubadas a $37{ }^{\circ} \mathrm{C}$, durante 72 horas, quando foram observados os halos. A atividade surfactante foi testada para todos os isolados, após separação parcial do líquido fermentado por precipitação com $\mathrm{HCl}$, centrifugação e solubilização do precipitado em água destilada, $\mathrm{pH}$ 11. As tensões superficiais da água pura e da água com adição do precipitado foram medidas com tensiômetro de Du Nouy.

Os tratamentos com e sem células não diferiram entre si e foram considerados como repetições do mesmo isolado. A eficiência de controle da mancha-aquosa pelos líquidos fermentados de Bacillus (Tabela 1) foi observada em todas as variáveis analisadas, PI, INC, IDO e AACPD. Utilizando B. megaterium pv. cerealis RAB7, obtevese redução da incidência (RINC) e do índice de doença (RIDO) de até 89,1 e $92,7 \%$, respectivamente. Esse mesmo isolado elevou o período de incubação da mancha-aquosa de 9,8 para 11,9 dias e reduziu a AACPD de 3,36 para 0,17 .

Os resultados in vivo sugerem que o mecanismo de antibiose seja o principal responsável pelo controle da mancha-aquosa do melão,

Tabela 1 - Efeito do tratamento de sementes de melão com fermentados de Bacillus subtilis R14, B. megaterium pv. cerealis RAB7, B. pumilus C116 e Bacillus sp. MEN2, no controle da mancha-aquosa causada por Acidovorax avenae subsp. citrulli, em casa de vegetação.

\begin{tabular}{lrrrrrr}
\hline Tratamentos & PI $^{1}(\mathrm{~d})$ & INC(\%) & RINC(\%) & IDO(\%) & RIDO(\%) & AACPD \\
\hline RAB7 & $11,87^{2} \mathrm{a}$ & $7,03 \mathrm{~b}$ & 89,1 & $2,96 \mathrm{~b}$ & 92,7 & $0,17 \mathrm{~b}$ \\
R14 & $11,62 \mathrm{a}$ & $19,38 \mathrm{~b}$ & 70,1 & $7,88 \mathrm{~b}$ & 80,6 & $0,41 \mathrm{~b}$ \\
C116 & $11,57 \mathrm{a}$ & $18,75 \mathrm{~b}$ & 71,1 & $7,81 \mathrm{~b}$ & 80,8 & $0,64 \mathrm{~b}$ \\
MEN2 & $11,50 \mathrm{a}$ & $16,51 \mathrm{~b}$ & 74,4 & $7,36 \mathrm{~b}$ & 81,9 & $0,73 \mathrm{~b}$ \\
Testemunha & $9,84 \mathrm{~b}$ & $64,72 \mathrm{a}$ & - & $40,75 \mathrm{a}$ & - & $3,36 \mathrm{a}$ \\
\hline
\end{tabular}

${ }^{1} \mathrm{PI}=$ Período de incubação; INC = Incidência da doença; RINC = Redução da incidência da doença; IDO = Índice de doença, calculado pela fórmula, IDO=! (grau da escala $\mathrm{x}$ freqüência) $\times 100 /\left(\mathrm{n}^{\circ}\right.$ total de unidades $\mathrm{x}$ grau máximo da escala) (5); RIDO = Redução do índice de doença; $\mathrm{AACPD}=$ Área abaixo da curva de progresso da doença, calculada pela fórmula AACPD $=1\left(\mathrm{y}_{\mathrm{i}}+\mathrm{y}_{\mathrm{i}+1}\right) / 2 . \mathrm{d}_{\mathrm{ti}} / \mathrm{n}$, onde $\mathrm{y}_{\mathrm{i}}$ e yi ${ }_{+1}$ são os valores de severidade observados em duas avaliações consecutivas, $d_{t i} o$ intervalo entre as avaliações e na duração do período de avaliação (9).

${ }^{2}$ Média de 8 repetições com 16 plantas; médias seguidas por letras diferentes em uma mesma coluna diferem significativamente pelo teste de Tukey a $1 \%$ de probabilidade. 
uma vez que o líquido sem células foi tão eficiente no controle da doença quanto o líquido com células. Asaka \& Shoda (1) também constataram que o líquido fermentado produzido por $B$. subtilis RB14 , com ou sem células, reduziu a incidência do tombamento de plântulas de tomateiro por Rhizoctonia solani. Confirmando esta hipótese, os quatro isolados de Bacillus testados produziram compostos ativos contra Aac in vitro. Além disso, os halos de hemólise formados pelos Bacillus em ágar sangue são um indicativo de que esses compostos são lipopeptídeos, sendo que $\mathrm{C} 116$ produziu o maior halo de hemólise, e MEN2, o segundo. Também Monteiro et al. (6) observaram a formação de halos de hemólise pelos isolados de Bacillus spp. R14, RAB7 e C116, sugerindo a produção de lipopeptídeos por esses isolados.

Evidência adicional de que os compostos são lipopeptídeos foi a redução da tensão superficial da água de $70 \mathrm{mN} / \mathrm{m}$ para $40-50 \mathrm{mN} / \mathrm{m}$ pelos precipitados resultantes da separação parcial de todos os isolados. Sabe-se que espécies de Bacillus produzem grande número de peptídeos, entre os quais lipopeptídeos, com amplo espectro de atividade antimicrobiana (7).

Desta forma, sugere-se que o controle da mancha-aquosa em plântulas de melão pelo tratamento de sementes seja devido aos compostos lipopeptídicos produzidos pelas espécies de Bacillus testadas.

\section{AGRADECIMENTOS}

Os autores são gratos à Fundação de Amparo à Ciência e Tecnologia do Estado de Pernambuco - FACEPE, pelo auxílio financeiro.

\section{REFERÊNCIAS BIBLIOGRÁFICAS}

1. Asaka, O.; Shoda, M. Biocontrol of Rhizoctonia solani damping-off of tomato with Bacillus subtilis RB14. Applied and Environmental Microbiology, Washington, v.62, n.11, p.4081-4085, 1996.
2. Kim, H.S.; Yoon, B.D.; Lee, C.H.; Suh, H.H.; Ho, M.H. Production and properties of a lipopeptide biosurfactant from Bacillus subtilis C9. Journal of Fermentation and Bioengineering, Osaka, v.84, n.1, p.41-46, 1997.

3. Mariano, R.L.R.; Assis, S.M.P. Inoculação de bactérias fitopatogênicas. In: Mariano, R.L.R. (Coord.). Manual de práticas em fitobacteriologia. Recife: Universidade Federal de Pernambuco, 2000. p.53-63.

4. Mariano, R.L.R.; Silveira, E.B.; Assis, S.M.P. Identificação de bactérias fitopatogênicas. In: Mariano, R. L. R. (Coord.) Manual de práticas em fitobacteriologia. Recife: Imprensa Universitária, Universidade Federal de Pernambuco, 2000. p. 67-108.

5. McKinney, H.H. Influence of soil temperature and moisture on infection of wheat seedlings by Helminthosporium sativum. Journal of Agriculture Research, Washington, v.26, n.5, p.195-218, 1923.

6. Monteiro, L.; Mariano, R.L.R.; Souto-Maior, A.M. Production of active compounds against Xanthomonas campestris pv. campestris by Bacillus species. In: SIMPÓSIO NACIONAL DE FERMENTAÇÕES, 14., 2003, Florianópolis. Anais... Florianópolis: Universidade Federal de Santa Catarina, 2003. p.1-7.

7. Nitschke, M.; Pastore, G.M. Biossurfactantes: propriedades e aplicações. Química Nova, São Paulo, v.25, n.5, p.777-776, 2002.

8. Sales Júnior, R.; Menezes, J.B. Mapeamento das doenças fúngicas, bacterianas e viróticas do cultivo do melão no estado do Rio Grande do Norte - RN. Mossoró: Escola Superior de Agricultura de Mossoró, 2001. 25p. Relatório Técnico.

9. Shaner, G.; Finney, R.E. The effect of nitrogen fertilization on the expression of slow-mildewing resistance in knox wheat. Phytopathology, St. Paul, v.67, n.8, p.1051-1056, 1977.

10. Silveira, E.B.; Mariano, R.L.R.; Michereff, S.J. Variabilidade de isolados de Acidovorax avenae subsp. citrulli provenientes de melão produzido no Estado do Rio Grande do Norte. Summa Phytopathologica, Botucatu, v. 29, n.3, p.255-261, 2003. 